\title{
A Basic Technical Analysis of Shares on the Example of a Specific Company
}

\author{
Jakub Horak ${ }^{1, *}$ and Jiri Sulek \\ ${ }^{1}$ Institute of Technology and Business in České Budejovice, Okružní 517/10, 37001 České \\ Budějovice, Czech Republic
}

\begin{abstract}
This paper deals with the technical analysis of The Coca-Cola Company (KO) shares. The first signal for the stock price movement was created on the basis of the intersections of moving averages, namely after intersecting the shorter average through the longer average. This signal signifies a drop in the share price. The same signal was generated after comparing the trend of the share price and the trend of the trading volumes. It is these particular trends that have a different direction. Consequently, this is an indicator for a decline in the share price. The last signal created a graphical pattern called symmetric bear triangle which also predicts a drop in the stock price. Only one indicator did not generate a signal for price increase or decrease, namely the RSI with a 14-day period. The examined data collection contains data from 2.1.2015 to 29.4.2020. At the same time, all presented results and predictions are based on the date of April 29, 2020. Finally, the use of the given indicators for different titles, assets or for different types of trade with different lengths is evaluated and proposed. The paper provides suggestions of measures for investors and speculators which should be applied before the start of the analysis. Keywords: stock market, time series, prediction, technical indicators, volatility
\end{abstract}

\section{Introduction}

Considering the global predictions of the impending next global crisis, the subject of stock market analysis is very topical. Should a greater or smaller financial crisis occur, it is almost certain that the stock values of most companies will fall by tens of percent. And this is exactly the right time for both large and small investors or small speculators who can increase the value of their capital in this period of economic depression [1-2]. The valuation can be solved by both short positions and long positions directly on the share or by the respective option on the share. Another possibility is a speculation on a commodity, a currency pair, a precious metal etc. It important to be familiar with the mechanisms of the stock market not only during a crisis but also at other times.

At this time, a lot of information can be found for free without much delay. That is the reason why people's interest in this type of business is growing. There are many ways to

*Corresponding author: horak@mail.vstecb.cz 
make money on stocks. They can be kept for a long time, which can generate passive income for the investor or increase the value of the invested capital. Quality stocks protect against inflation, and even trend more than inflation. Other investors may use the equity portfolio as a way to saving for themselves or for future generations. Another possibility is a short-term speculation on the movement of the stock price or stock index, in the time frame reaching from a few minutes to several months [3-4].

The analysis of the share time series is performed by a technical analysis, which represents the basic methodology for finding the optimal entry into the trade. It uses many indicators which include supports and resistance, trend periodical, the number, strength and type of open trades of individual positions and many others.

The advantage of stock trading is the unlimited potential of choosing a strategy, as well as a theoretically unlimited profit. On the other hand, it is possible to lose the whole invested capital in a few minutes. Another advantage is the fact that the speculator's result is not influenced by any direct colleague affecting the result. Everything is up to the speculator's or investor's ability to analyse, predict, experience, etc.

This paper will be dealing with the shares of The Coca-Cola Company (ticker KO). The reason for choosing this particular company is the strength of this brand on its respective market where it is the number one player and its strength on the global stock market as well. The quality and strength of the company is easy to present as the company ranks among the dividend kings. This means that for more than 50 years, the company has been increasing the number of dividends paid per share year-on-year. In the case of Coca-Cola, the company managed to keep this state for 57 years. The Coca-Cola shares are traded on the New York Stock Exchange (NYSE).

The aim of the paper is to find the optimal position to enter the trade, either long position or short position for swing trade, depending on the analysis of the historical trending of the particular stock and the trending of other dividend kings, indices and competitors in the same industry.

\section{Literature Research}

The first indicator that is examined by a stock trader without the need for employing mathematical procedures is a trend. It is either rising (bull) or falling (bear) [5]. To decide whether a trader will speculate on the increase (bull) or rather on a decrease (bear) in the share price. Trend recognition is a basic pattern of a technical analysis. Trends are very often repeated, either cyclically or seasonally [6]. The cyclical component of the trend is repeated after more than a year, the seasonal component, on the other hand, usually within one year. It is important to be aware of the fact that the price trend appearing on the price chart, be it rising or falling, is never endless. Every trend has its beginning and end. The end of the trend can be observed based on the combination of Japanese candles on the price chart [7]. The Japanese candle is one of the most popular price level representations in a chart. The candle itself contains four pieces of information: the price at the time of opening, the price at the time of closing, the minimum price in the time interval and the maximum price in the time interval. The Japanese candle appears in two colour variants depending on the rising or falling tendency of the price [5]. The trends are further divided into short-term and long-term ones [8-9]. It may occur that the limited trend is bearish but the long-term trend is bullish and the other way around.

One of the most used technical indicators is the moving average (MA). The moving average can be defined according to the required conditions. It is an average that calculates the past data serving as a foundation for the calculation of the average. The 50-day and 200day simple moving average (SMA) are the two most used types. Other moving averages are 
WMA - weighted moving average, KAMA - Kaufman's adaptive moving average, EMA exponential moving average, LWMA - linear weighted moving average, etc. These averages have a modified calculation [10]. The moving average is used for a clearer detection of a trend which may seem confusing on a classic price chart, for example due to high price volatility [11]. Combining two moving averages with different periods creates a signal for opening a long or a short position (the same types of MA). For the long position, the signal is created when the MA with a shorter period intersects the MA with the longer period from the bottom. For a short position, the signal is generated when an MA with a shorter period intersects an MA with a larger period from above [9].

The RSI, or relative force index, is one of the very popular oscillators that ranks among the technical indicators. This indicator graphically represents the internal strength of the underlying asset. On this basis, it sends signals about the overbought or oversold state of a particular asset [12]. RSI works with past data and is one of the short-term to medium-term indicators [13]. RSI can detect deviations in market behaviour. At the same time, it operates with fixed indication levels and it is only up to the trader whether they use the signal at the first hint or whether they wait for a repeated signal [14]. The RSI values range from 0 to 100. The signal generation levels are set at level 30 (growth signal) and 70 (decrease signal) by default. The 30/70 levels are the most suitable to use for a 14-day RSI [14]. For 20-day RSI, the levels are adjusted to 40/60 [15].

Another factor frequently used for trading on the stock market is volatility which indirectly indicates how risky a specific underlying asset is. Volatility is a fragmentation of the market and it is directly linked to the amount of open positions. The bigger and more numerous the trades, the higher the volatility and, consequently, the potential risk [16-18]. The higher the volatility of an asset, the riskier the trade but also more profitable at the same time [19]. Volatility can be influenced by large investors, especially investment funds, states, hedge funds, etc. disposing of large amounts of money triggering price movements of a given asset [20]. This, on the other hand, can lure small retail investors and speculators away. Small speculators avoid great volatility as the significant movement of an asset can drain their capital in a few hours or days [21]. High volatility on the market occurs especially during a financial crisis and a recession where there is an increased risk of bankruptcy [20]. Another factor that increases uncertainty and market volatility is political uncertainty in both local and global areas, mainly for assets that are directly dependent on the behaviour of the state apparatus [22].

Currently, the opportunity to analyse the time series of exchange-traded assets using neural networks has widely spread. Market analysis based on neural networks is especially suitable for intraday trading or scalping. Neural networks can extract specific functions from a large amount of source data, without knowledge of past predictors and success indicators.

From the available sources, it is obvious that it is possible to perform a time series analysis using basic technical indicators that are suitable for beginners [10] but also for portfolio managers in various companies, option speculators but also for small experienced investors [8].

Three indicators will be used for the basic technical analysis of the time series in this paper, namely moving averages, RSI and trade volumes. For their simplicity and efficiency, these indicators are mentioned in the literature dealing with this issue the most often. Based on the use of these indicators, it will be possible to determine whether the trend in the development of the share price will continue, go sideways or reverse. Thanks to this, it is possible to determine the optimal share price for entering the trade, the type of trade and the length of the trade. 


\section{Data and Methods}

The price movement in one trading day or one monitored interval is determined by four values that are most often graphically displayed in form of the Japanese candle (Figure 1). These values are: minimum price, maximum price, price at the time of opening and price at the time of closing.

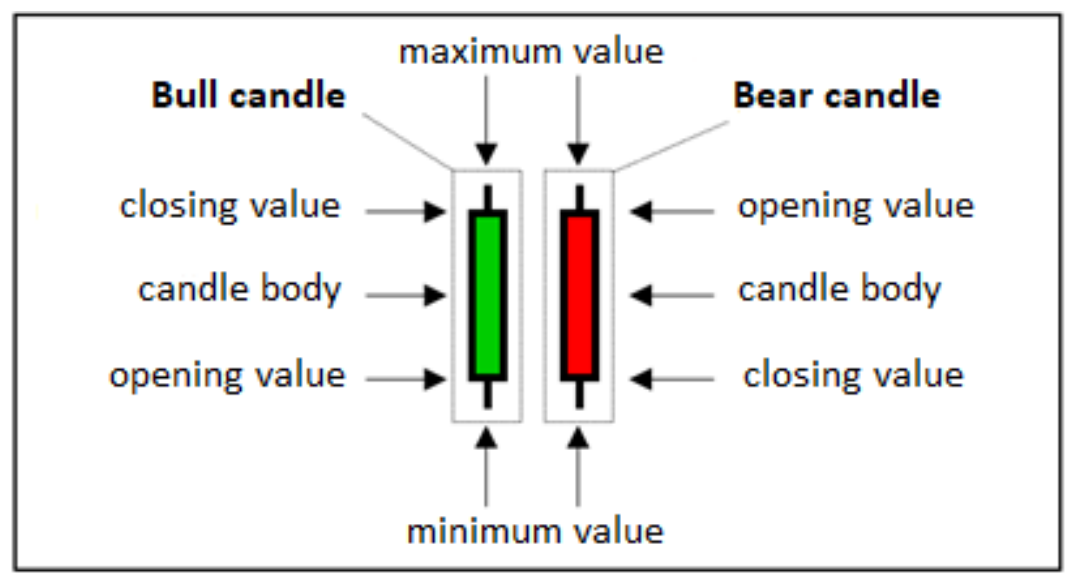

Fig. 1. The Japanese Candle

Source: Authors.

It is exactly the combination and size of these candles that determines the trend on the market. The data file was obtained from Yahoo Finance [23]. It contains data for the last 5 years, more precisely 1,339 stock exchange days. The start date is 2015/01/02 and the end date is 2020/04/29. The data file contains information about the sums that can be graphically represented by the Japanese candle. The graphic representation will show the development of the stock price from 2020/07/01. In addition to that, the data file contains information about the amount of open trading positions. All price levels are given in USD / 1 stock format. An example of the data structure is shown in the Table 1, with the data in the example stemming from one-month long intervals. All calculations will be performed from the daily data.

Table 1. Structure of the data file classification

\begin{tabular}{|c|l|l|l|l|l|}
\hline Date & \multicolumn{1}{|c|}{ Open } & \multicolumn{1}{c|}{ High } & \multicolumn{1}{c|}{ Low } & Close & Volume \\
\hline 29.04 .2019 & 48.17 & 48.45 & 48.11 & 48.42 & $9,731,500$ \\
\hline 28.05 .2019 & 49.60 & 49.67 & 49.03 & 49.10 & $18,614,000$ \\
\hline 27.06 .2019 & 51.29 & 51.40 & 50.97 & 51.08 & $12,374,900$ \\
\hline 26.07 .2019 & 53.34 & 54.31 & 53.19 & 54.17 & $11,451,900$ \\
\hline 27.08 .2019 & 54.70 & 54.95 & 54.41 & 54.72 & $13,537,000$ \\
\hline 27.09 .2019 & 54.56 & 54.64 & 54.00 & 54.31 & $7,939,900$ \\
\hline 28.10 .2019 & 53.74 & 53.95 & 53.37 & 53.57 & $8,866,100$ \\
\hline 27.11 .2019 & 53.93 & 54.10 & 53.60 & 53.95 & $9,595,200$ \\
\hline 27.12 .2019 & 55.01 & 55.45 & 55.00 & 55.35 & $6,895,500$ \\
\hline 27.01 .2020 & 57.21 & 57.85 & 57.13 & 57.48 & $14,359,900$ \\
\hline 27.02 .2020 & 57.15 & 57.89 & 54.88 & 54.93 & $23,754,000$ \\
\hline 27.03 .2020 & 43.66 & 44.03 & 42.40 & 42.81 & $23,297,900$ \\
\hline 27.04 .2020 & 46.00 & 46.81 & 45.71 & 46.62 & $15,175,000$ \\
\hline
\end{tabular}

Source: Authors. 
In order to perform a technical analysis, it is necessary to use a basic indicator which is the moving average. The 50-day, 100-day and 200-day simple moving averages are used to analyze The Coca-Cola Company stock by applying the following formula:

Where:

$$
S M A n_{p}=\frac{1}{n} \sum_{t=p-n+1}^{n} c_{i}
$$

$S M A$ - simple moving average,

$n$ - length of the moving average calculation period,

$p$-current position of the observed period,

$c_{i}-$ the closing price of the share on the stock exchange day.

An exponential moving average (EMA) is very often used as well. The difference between EMA and SMA is the following: EMA puts more emphasis on newer data and "forgets" older data. EMA is, therefore, more sensitive to current market developments. EMA is calculated by the following formula:

Where:

$$
E M A n_{p}=\left(\frac{2}{n+1}\right) * c_{i}-1\left(1-\left(\frac{2}{n+1}\right)\right) * E M A n_{p-1}
$$

$E M A$ - exponential moving average,

$n$ - length of the moving average calculation period,

$p$-current position of the observed period,

$c_{i}$ - closing price of the stock in the stock exchange,

$E M A n_{p-1}$ - moving average from the previous day.

Further information about a given asset can be read from the values of the relative strength index (RSI) which belongs to the group of leading indicators. This means that such indicator provides a signal even before the events on the market start to develop in a certain direction. At the same time, this indicator is measurable and belongs to the group of oscillators. Mathematically and graphically, RSI represents the oversold or overbought state of a given asset. It can also be used to confirm a particular trend. Another feature of the RSI indicator is the fact that under standard conditions, its development on the chart has a similar trend as the price chart of the examined asset. To calculate the RSI value, the following formula applies:

Where:

$$
R S I=100-\left(\frac{100}{1+R S}\right)
$$

$R S I$ - relative force index,

$R S$ - the ratio of the average change in the asset price.

To calculate RSI, it is necessary to know the RS ratio calculated by the following relation:

Where:

$$
R S=\frac{A V G \text { gain }}{A V G \text { loss }}
$$

$A V G$ gain - average increase in the asset price for the observed period, $A V G$ loss - average decrease in the asset price for the observed period.

As far as RSI is concerned, the following applies: 
a) $\mathrm{RSI}<\mathbf{3 0}$ the market is oversold; signal for trend growth.

b) $30<$ RSI $<70$ the market is neutral; the trend continues.

c) $70<$ RSI the market is overbought; signal for a downward trend.

For the purposes of this paper, the calculation is made with a 14-day period, which is also the most used period in general.

The movement of the stock price trend can be predicted from the volume of trades of a given stock. As trading volumes increase, so does the volatility of the asset price, and so does the risk of the trade. Dow Theory argues that volumes must confirm the trend. There are four trend relationships between trading volumes and asset price developments. Specifically, it describes four situations that are recognized and used even today [24]. These rules are:

Table 2. Relationship between trading volumes and asset price development

\begin{tabular}{|l|l|l|}
\hline \multicolumn{1}{|c|}{ Actual Trend } & \multicolumn{1}{c|}{ Trading Volumes } & \multicolumn{1}{c|}{ Future Trend Prediction } \\
\hline Rising (bull) trend & Rising & Rising (bull) trend \\
\hline Rising (bull) trend & Falling & Falling (bear) trend \\
\hline Falling (bear) trend & Rising & Falling (bear) trend \\
\hline Falling (bear) trend & Falling & Rising (bull) trend \\
\hline
\end{tabular}

Source: Authors.

From this model, it can be concluded that the increasing trade volumes confirm the trend while declining trade volumes stop and reverse the trend.

The trend has its imaginary boundaries which determine the already mentioned sideways direction, bull trend or bear trend. These boundaries are represented by support and resistance. Supports limit the trend from below and do not drop the price below this level. Resistance limits the trend from above and does not drop the price above this level. These two levels can go parallel, in opposite directions or towards each other. Based on the direction of these boundaries, a pattern of trend movement can be recognized and it can be predicted how and when the trend will change. In addition to that, these patterns help set the stop loss. On the price chart, the presence of any of the patterns will be examined, such as head-shoulders, bear or bull rectangle, rising or falling, or symmetrical triangle.

After the application of the above-mentioned methods, the results will be presented in a graphic form where moving averages and trading volumes will be illustrated. Furthermore, a separate graph for the RSI values will be created. If a pattern based on supports and resistances is indicated, it will be graphically highlighted in the price chart. Subsequently, the development of the stock price time series will be graphically indicated. Finally, an overview representing all the used indicators and predictions based on their value will be created.

\section{Results}

Technical indicators were calculated from the data set using the above-mentioned mathematical apparatus. The calculations were performed using Excel software from Microsoft. First, the moving average for its 50-day, 100-day and 200-day variant was calculated. For an easier presentation, all three averages were projected into a graph of the asset price. At the same time, all three averages are calculated for each day of the observed period and they change dynamically. It can be confirmed from the chart that the average with a shorter period reacts faster to a change in the price of an asset. Currently, the value of the averages with the shortest period is the lowest. With the increasing period, the value increases as well. 
Next, the RSI indicator was calculated with a 14-day period, which is generally the most used one. The resulting model values are calculated for each day of the observed period in order to graphically display the trend of the RSI development. The limit for the overbought signal is set at 70 , for the oversold signal then at 30 . The resulting value amounts to approximately one month at a neutral value around 50 .

Other values reflected in the chart are the volumes of trades executed in one day. These values were included in the basic data file and are marked as volume in the graph. The resulting display shows a clear declining trend in volumes.

The next indicator is not calculated mathematically, the values of the asset price and the development of trading volumes are represented only in a graphical way. The chart shows the opposite trend between the price of the asset and the development of volumes in the short term $(2020 / 03 / 2020$ - now).

Finally, the trend limits, one resistance and one support were projected into the graph. These boundaries converge over time forcing the price of the asset to trend sideways in an ever-smaller range. Such a push is classically followed by a burst of support or resistance, and the price moves quickly in one direction.

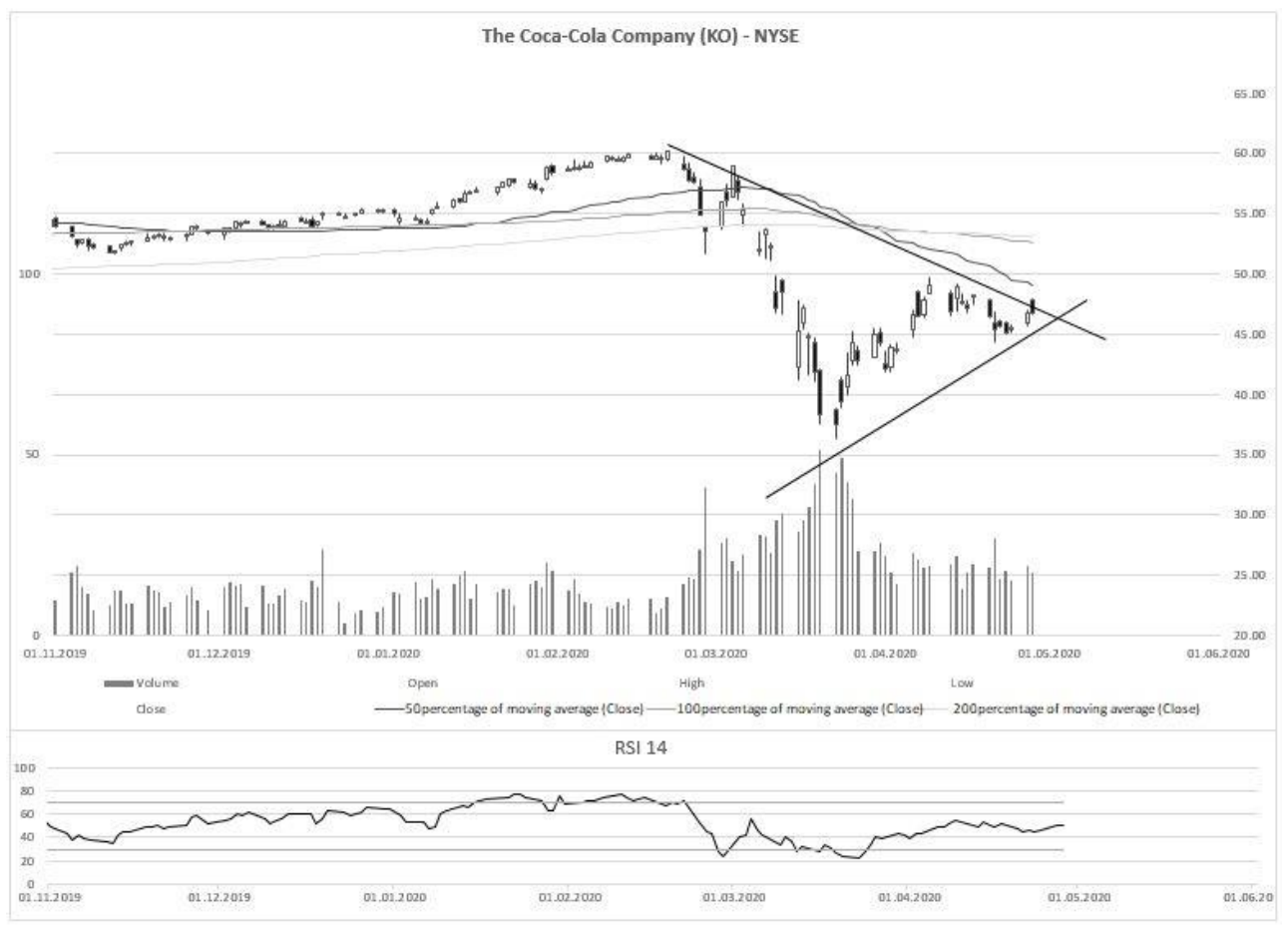

Fig. 2. The development of the KO stock price and the representation of technical indicators

Source: Authors.

\section{Discussion}

In the preceding chapter, five signals were evaluated which indicated the total of four signals for the short position. One result was at a neutral value, which indicates price movement to sideways or a slight trending which is not suitable for scalping, intraday or swing trading. 
The first two signals are caused by the movement of the moving averages, the always shorter simple moving average intersecting the average with the higher period. This signal was confirmed in the case of moving the SMA200 and SMA100, but also in the case of moving the SMA100 and SMA50. Both SMA-based signals apply for the short position. Another indicator did not generate any trading signal, as the value of the RSI with a 14-day period stayed for 1 month around the value 50. According to this indicator, it is not appropriate to open any trading position now, as there is no indication of future movements in asset prices. Another signal was indicated on the basis of the movement development of the asset price and the movement development of the trading volumes, at the same time. With the help of a graphical representation of these waveforms, the opposite trend is noticeable in the short term. According to the Dow Theory [24], given the different course of these two trends, it is expected that the asset price trend will stop and reverse, which, in the case of $\mathrm{KO}$, should turn down, thus supporting the short position. The last signal was indicated after the projection of support and resistance for the last two months. A symmetrical triangle was created on the price chart. Support and resistance force the price to trend sideways in an ever-smaller range. Such compression is followed by the rupture of one of these boundaries. The price of the asset began to form this triangle around 2020/03/01, with a sharp decline. The direction in which the asset enters the triangle is the one that tends to break through the resistance line and move sharply in that direction. In this case, there is a signal that the price will break through the support and will fall, i.e. a signal to open a short position. Over time, there is the possibility of developing resistance with a simple 50-day moving average. In the case of KO shares, four short signals out of five possible were created, so there is a great assumption of a decline in the share price. An overview of indicators and signals is clearly written in the table below.

Table 3. Indicators and signals of the KO share price development - an overview of the Coca-Cola company $(\mathrm{KO})$ technical analysis

\begin{tabular}{|c|c|c|}
\hline Indicator & Development & Signal \\
\hline $\begin{array}{c}\text { Simple moving average } \\
\text { SMA200 - SMA100 }\end{array}$ & $\begin{array}{c}\text { SMA100 intersected SMA200 from } \\
\text { above and falls slightly }\end{array}$ & Short \\
\hline $\begin{array}{c}\text { Simple moving average } \\
\text { SMA100 - SMA50 }\end{array}$ & $\begin{array}{c}\text { SMA50 intersected SMA100 from } \\
\text { above and falls steeply }\end{array}$ & Short \\
\hline RSI index RSI14 & $\begin{array}{c}\text { One month on a neutral level at about } \\
50\end{array}$ & Do not trade \\
\hline Price trend vs. Volume trend & $\begin{array}{c}\text { Asset price rises but trade volumes } \\
\text { fall }\end{array}$ & Short \\
\hline Graphical pattern & Symmetrical bear triangle & Short \\
\hline
\end{tabular}

Source: Authors.

Although $80 \%$ of the signals indicate a fall in the price of an asset, it is important to keep in mind that the value of a stock is also affected by fundamental factors which may indicate the same as well as the opposite signals. It is always better to perform both a technical and a fundamental analysis. Especially in the time of a coronavirus pandemics, it is important to take into account fundamental factors. At the same time, it is appropriate to wait for the official publication of economic results for the first quarter of 2020 and to observe its effect on the share price. The results were published on April 21, 2020. Indicators that are more suitable for short-term speculation were used in the technical analysis of KO. In the case of an analysis with the intention of holding shares in the long run, other indicators would be more suitable.

Before performing a technical analysis, a speculator or investor must consider what type of trade he wants to open. If they want to open a position for scalping or for intraday 
trading, they use the above-mentioned indicators with a shorter period, for example RSI with period 9. Furthermore, for such a short trade, it is not appropriate to examine the ratio between moving averages. For such a short trade, it is more suitable to focus on the graphic patterns that create the price of the asset. On the other hand, for longer-term trades, the speculator will make more use of long periods for indicators and will put more emphasis on the fundamental analysis. It is also important to consider what level of risk the speculator wants to take and whether they will look for more volatile assets that generate higher profits but also losses. A more conservative speculator will use assets with lower volatility and will trade with lower leverage. For such type of trade, stock indices are a good option, for example in the form of ETF or option spread strategies.

\section{Conclusion}

The aim of this paper was to analyze the time series of the stock and then to predict its future development. In this paper, the shares of The Coca-Cola Company (KO) were analyzed, in which case five technical indicators were further examined. Their use is minutely described in the chapter concerned with data collection and methodology. Subsequently, the results of the analysis were presented and evaluated. Out of the five examined indicators, a signal for a decrease in price appeared four times creating a prediction of a decrease and fulfilling the goal of the paper. The suitability and effectiveness of using the indicators for technical analysis is confirmed by their high popularity with large speculators and investors or investment and hedge funds for decades. Another factor that adds credibility to the indicators is based on the large number of professional, scientific or conference papers that are available on professionally recognized databases, which is confirmed in the chapter presenting the literary research. The technical analysis based on the same indicators is also suitable for other stocks or for other types of assets, as all used indicators work only with the price of the asset. There is no limiting time frame for technical analysis determining when the analysis is to be performed. The values change dynamically over time so the asset can be analyzed at any time. In the future, it would be interesting to perform a technical analysis using the same indicators on different types of assets, repeatedly. Other assets include cryptocurrencies, currency pairs, commodities or options, and finally compare the effectiveness of applying the same analysis to different assets.

In conclusion, it can be stated that, on the basis of the performed analysis, the KO share expects a price decrease, which is predicted by four out of the five indicators that were used in the paper. The goal of the paper has been met.

\section{Acknowledgements}

This article was funded within the project SVV202007 "Creation of a research report for scientific research activities of students at the Institute of Technology and Business in České Budějovice".

\section{References}

1. M. Vochozka, J. Horak, T. Krulicky, Innovations in management forecast: Time development of stock prices with neural networks. Marketing and Management of Innovations, 2020(2), 324-339 (2020)

2. P. Suler, J. Horak, T. Krulicky, Validation of the prediction of ČEZ stock prices. Littera Scripta, 13(1), 194-210 (2020) 
3. J. Vrbka, Z. Rowland, Stock price development forecasting using neural networks. SHS Web of Conferences - Innovative Economic Symposium 2017: Strategic Partnership in International Trade (2017)

4. B. Groda, J. Vrbka, Prediction of stock price developments using the Box-Jenkins method. SHS Web of Conferences - Innovative Economic Symposium 2017: Strategic Partnership in International Trade (2017)

5. H. Zhou, Y. He, Y.X. Jin, Modelling for forecasting of pattern recognition - based on comparison and analysis be-tween U.S. stock market and Chinese stock markets. Proceedings of the 2016 International Conference on Applied Mathematics, Simulation and Modelling, 41, pp. 1-5 (2016)

6. D. Stramirovic, D. Sarvan, V. Miljkovic, S. Blesic, Analysis of cyclical behavior in time series of stock market returns. Communications in Nonlinear Science and Numerical Simulation, 54, 21-33 (2018)

7. L.J. Chmielewski, M. Janowicz, A. Orłowski, Advances in intelligent systems and computing. Springer Verlag, 403, pp. 641-647 (2016)

8. A. Kolkova, Indicators of technical analysis on the basis of moving averages as prognostic methods in the food industry. Journal of Competitiveness, 10, 102-119 (2018)

9. M. Frömmel, K. Lampaert, Does frequency matter for intraday technical trading? Finance Research Letters, 18, 177-183 (2016)

10. T. Shalini, S. Pranav, S. Utkarsh, Picking buy-sell signals: A practitioner's perspective on key technical indicators for selected Indian firms. Studies in Business and Economics, 14, 205-219 (2019)

11. V.A. Sobreiro, T.R.C.C. da Costa, R.T.F. Nazario, J.L.E. Silva, E.A. Moreira, M.C. Lima, H. Kimura, J.C.A. Zambrano, The profitability of moving average trading rules in BRICS and emerging stock markets. North American Journal of Economics and Finance, 38, 86-101 (2016)

12. P. Marek a B. Sediva, Optimization and testing of RSI. In: Financial management of firms and financial institutions. Ostrava: VŠB-Technical University of Ostrava, Czech Republic, pp. 530-537 (2017)

13. F. García, F. Guijarro, J. Oliver, R. Tamošiūnienè, Hybrid fuzzy neural network to predict price direction in the German DAX-30 index. Technological and Economic Development of Economy, 24, 2161-2178 (2018)

14. B.W. Crowell, Y. Bock, Z. Liu, Single-station automated detection of transient deformation in GPS time series with the relative strength index: A case study of Cascadian slow slip. Journal of Geophysical Research: Solid Earth, 121, 9077-9094 (2016)

15. P. Rihova, M. Svoboda, Profitability of selected technical analysis indicators. European Financial Systems 2018: Proceedings of the $15^{\text {th }}$ International Scientific Conference, pp. 591-598 (2018)

16. I. Podhorska, K. Valaskova, V. Stehel, T. Kliestik, Possibility of company goodwill valuation: Verification in Slovak and Czech Republic. Management \& MarketingChallenges for the Knowledge Society, 14(3), 338-356 (2019)

17. K. Valaskova, T. Kliestik, L. Svabova, P. Adamko, Financial risk measurement and prediction modelling for sustainable development of business entities using regression analysis. Sustainability, 10(7) (2018)

18. A. Moreira, T. Muir, Volatility-managed portfolios. Journal of Finance, 72, 1611-1644 (2017)

19. S. Basak, A. Pavlova, A model of financialization of commodities. Journal of Finance, 71, 1511-1556 (2016) 
20. S.R. Baker, N. Bloom, S.J. Davis, Measuring economic policy uncertainty. Quarterly Journal of Economics, 131, 1593-1636 (2016)

21. A. R. Arévalo Murillo, Short-term forecasting of financial time series with deep neural networks. Thesis: Ingeniería de Sistemas (2016)

22. E. Chong, C. Han, F.C. Park, Deep learning networks for stock market analysis and prediction: Methodology, data representations, and case studies. Expert Systems with Applications, 83, 187-205 (2017)

23. The Coca-Cola Company (KO). Yahoo Finance [online]. Available at: https://finance.yahoo.com/quote/KO/history?p=KO (2020)

24. A. Hayes. Investopedia [online]. New York. Available at: https://www.investopedia.com/terms/d/dowtheory.asp (2019) 